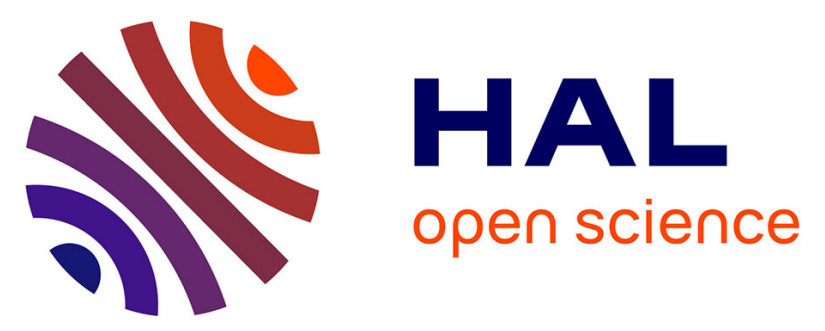

\title{
Indocyanine green fluorescence imaging to predict graft survival after orthotopic liver transplantation: a pilot study
}

Damien Dousse, Eric Vibert, Quentin Nicolas, Muga Terasawa, Luis Cano, Marc-Antoine Allard, Chady Salloum, Oriana Ciacio, Gabriella Pittau, Antonio Sa Cunha, et al.

\section{To cite this version:}

Damien Dousse, Eric Vibert, Quentin Nicolas, Muga Terasawa, Luis Cano, et al.. Indocyanine green fluorescence imaging to predict graft survival after orthotopic liver transplantation: a pilot study. Liver Transplantation, 2020, 26 (10), pp.1263-1274. 10.1002/lt.25796 . hal-02635121

\section{HAL Id: hal-02635121}

\section{https://hal-univ-rennes1.archives-ouvertes.fr/hal-02635121}

Submitted on 15 Jun 2020

HAL is a multi-disciplinary open access archive for the deposit and dissemination of scientific research documents, whether they are published or not. The documents may come from teaching and research institutions in France or abroad, or from public or private research centers.
L'archive ouverte pluridisciplinaire HAL, est destinée au dépôt et à la diffusion de documents scientifiques de niveau recherche, publiés ou non, émanant des établissements d'enseignement et de recherche français ou étrangers, des laboratoires publics ou privés. 
DR. DAMIEN DOUSSE (Orcid ID : 0000-0002-3654-2309)

DR. NICOLAS GOLSE (Orcid ID : 0000-0002-5261-1538)

Article type : Original Articles

Indocyanine green fluorescence imaging to predict graft survival after orthotopic liver transplantation: a pilot study

Damien Dousse ${ }^{1,2,3}, \mathrm{MD}$, Eric Vibert ${ }^{1,2}, \mathrm{MD}, \mathrm{PhD}$, Quentin Nicolas ${ }^{4}$, Muga Terasawa ${ }^{1}, \mathrm{MD}$, Luis Cano $^{5}, \mathrm{MD}, \mathrm{PhD}$, Marc-Antoine Allard ${ }^{1,2}, \mathrm{MD}, \mathrm{PhD}$, Chady Salloum ${ }^{1}, \mathrm{MD}$, Oriana Ciacio ${ }^{1}, \mathrm{MD}$, Gabriella Pittau¹, MD, Antonio Sa Cunha ${ }^{1,2}, \mathrm{MD}$, Daniel Cherqui ${ }^{1,2}, \mathrm{MD}$, PhD, René Adam ${ }^{1,6}, \mathrm{MD}$, $\mathrm{PhD}$, Didier Samuel ${ }^{1,2}, \mathrm{MD}, \mathrm{PhD}$, Irene Vignon-Clementel ${ }^{4}, \mathrm{PhD}$, Nicolas Golse ${ }^{1,2,4}, \mathrm{MD}$.

1. Department of Hepato-Biliary and Liver Transplant, AP-HP Paul Brousse Hospital, Centre Hépato-Biliaire, Villejuif, France.

2. Inserm Unit 1193, Villejuif, France.

3. Department of Digestive Surgery, Rangueil University Hospital, Toulouse, France.

4. Inria, Paris, France.

5. Inserm Unit 1241, Rennes, France.

6. Inserm Unit 985, Villejuif, France.

\section{Keywords:}

Indocyanine green dye - Near-infrared fluorescence - Graft function - Primary non-function Modelling

\section{Corresponding author:}

Dr Nicolas Golse

Department of Surgery,

AP-HP Hôpital Paul Brousse, Centre Hépato-Biliaire,

14 Avenue Paul Vaillant Couturier, 
94800 Villejuif, France.

E-mail: nicolasgolse@me.com

\section{Abbreviations:}

AUC: area under the curve

BMI: body mass index

$\mathrm{Cl}$ : confidence interval

EAD: early allograft dysfunction

FI: fluorescence intensity

ICG: indocyanine green

ICGK: plasma clearance rate of ICG

ICU: intensive care unit

LCEOT: lactate concentration at the end of LT

LT: liver transplantation

NASH: non-alcoholic steato-hepatitis

NIR: near infra-red

MELD: model for end-stage liver disease

PGD: primary graft dysfunction

PNF: primary non-function

POD: postoperative day

ROC: receiver operating characteristic curve

ROI: region of interest

OR: odds ratio

\section{Conflict of interest:}

The authors declare no conflicts of interest. No funding sources were used.

\section{ABSTRACT \\ Introduction}

The incidence of primary non-function (PNF) after liver transplantation (LT) remains a major concern with the increasing use of marginal grafts. Indocyanine green (ICG) fluorescence is an 
imaging technique used in hepatobiliary surgery and LT. Because few early predictors are available, we aimed to quantify in real time the fluorescence of grafts during LT to predict their 3 months survival.

\section{Patients and Methods}

After graft revascularization, ICG was intravenously injected, then the fluorescence of the graft was captured with a near infrared camera and postoperatively quantified. A multi-parametric modelling of the parenchymal fluorescence intensity curve was proposed, and a predictive model of graft survival was tested.

\section{Results}

Between July 2017 and May 2019, 76 LT were included, among which 6 recipients were retransplanted $\left(\mathrm{re}-\mathrm{LT}^{+}\right)$. No side effects of ICG injection were observed. The parameter $a_{150}$ (temporal course of fluorescence intensity) was significantly higher in the group re-LT ${ }^{+}$group $\left(0.022 \mathrm{~s}^{-1}[0.016-0.035]\right.$ versus $\left.0.012 \mathrm{~s}^{-1}[0.009-0.015], \mathrm{p}=0.01\right)$. This parameter was the only independent predictive factor of graft survival at 3 months $\left(O R=2.4 \mathrm{Cl}_{95 \%}[1.05-5.5] \mathrm{p}=0.03\right)$. The best cut-off for the parameter $a_{150}\left(0.0155 \mathrm{~s}^{-1}\right)$ predicted the graft survival at 3 months with a sensitivity of $83 \%$ and a specificity of $79 \%(A \cup C=0.82$ [0.67-0.98], $p=0.01)$.

\section{Conclusion}

Quantitative assessment of intraoperative ICG fluorescence on the graft was feasible to predict graft survival at 3 months with a good sensitivity and specificity. Further prospective studies should validate these results over larger cohorts and evaluate the clinical impact of this tool.

\section{INTRODUCTION}

Liver transplantation (LT) is the best curative treatment for chronic liver diseases, hepatocellular carcinoma and acute liver failure. Because of the current organs shortage, marginal grafts from extended-criteria donors are routinely used (1)(2)(3). However, the main concern with these marginal grafts is the higher risk of primary graft dysfunction (PGD), that negatively impacts patient and graft survival (1)(2). PGD is defined as an early allograft dysfunction (EAD) and/or primary non-function (PNF) (4)(5)(6)(7). EAD is defined by the presence of biological abnormalities during the first 7 days after LT, according to the criteria described by Olthoff et al. (4), whereas PNF is defined as the lack of graft function following LT leading to death or retransplantation within 7 or 10 days (5)(8). The incidence of EAD ranges from 9 to $25 \%$, and that of PNF ranges from $0.9 \%$ to $7 \%(4)(6)$. 
In the field of LT, many predictive factors of graft dysfunction and graft survival have been reported (6)(7). However, these predictors require some days to be quantified and consequently, the delay for decision-making process may be detrimental for graft and/or patient survival. Despite a rich literature, there are very few early predictive factors to assess graft survival (5)(8), in order to re-transplant rapidly the patient if required (9). As well, the decision to retransplant remains difficult and based on non-consensual factors and cut-offs.

Indocyanine green (ICG) is a fluorescent dye used in hepatobiliary surgery to assess liver function for planning the hepatic resection extent, due to its selective hepatic uptake and its exclusive elimination in bile without enterohepatic recirculation and metabolism (10)(11). ICG is a near-infrared (NIR) fluorophore, emitting fluorescence at $830 \mathrm{~nm}$ when excited by a light with wavelength from 750 to $810 \mathrm{~nm}$ (10). Intraoperative ICG fluorescence imaging has been recently reported to evaluate graft function and to predict $P G D$, by a qualitative assessment of the type of graft fluorescence (8)(12). In a previous report, we showed that an abnormal ICG fluorescence pattern was a predictor of PGD after LT (8). However, this qualitative analysis is subjective and may be considered as operator-dependent. This technique has also been reported to assess liver function, by a quantitative analysis of parenchymal fluorescence intensity ( $\mathrm{FI}$ ) before hepatic resection (13)(14)(15). To the best of our knowledge, quantitative analysis of intraoperative ICG fluorescence imaging has never been used in the LT setting as a predictor of graft survival.

The objectives were first to determine the tolerability and safety of this imaging technique, then to quantify during LT the ICG fluorescence of the revascularized graft, and to predict the graft survival at 3 months. 


\section{PATIENTS AND METHODS}

\section{Study Population}

This prospective monocentric study was carried out at a tertiary center. Patient $\geq 18$ years old who underwent LT were eligible, regardless of the indication for LT or the type of graft.

The study was conducted in accordance with the Declaration of Helsinki, and conformed to good clinical practice guidelines. All patients provided written informed consent prior to enrolment.

\section{Preparation of ICG and the NIR Fluorescence Imaging System}

As a routine practice, the ICG fluorescent dye (Infracyanine ${ }^{\circledR}$, SERB Laboratories, Paris, France) was used for NIR fluorescence imaging of the graft. ICG (25mg vials) was re-suspended in $100 \mathrm{~mL}$ of $5 \%$ dextrose solution for injection to yield a stock solution of $0.25 \mathrm{mg} / \mathrm{mL}$. From this solution, the dose of ICG administered was adapted to body weight $(0.01 \mathrm{mg} / \mathrm{kg}$ body weight).

The Fluobeam ${ }^{\circledR}$ (Fluoptics SAS, Grenoble, France) fluorescence system for intraoperative imaging was previously described (8). For stable acquisition, the Fluobeam ${ }^{\circledR}$ was fixed on the Fluopod $^{\mathrm{TM}}$ (Fluoptics SAS, Grenoble, France), an articulated support arm. This imaging system allows subsequent quantification of the intensity of the fluorescent signal.

\section{Surgical Procedures}

Deceased donor LT, split LT, domino LT or living donor LT were performed using previously described techniques (16)(17)(18)(19). Before biliary anastomosis, intraoperative doppler ultrasonography was systematically performed by the surgeons for vascular patency assessment (Hitachi Aloka Medical, Tokyo, Japan). At the end of LT, a liver biopsy was always performed to assess graft steatosis and ischemia-reperfusion lesions (20).

\section{NIR Fluorescence Imaging of the Graft and Quantitative Analysis}


After revascularization of the graft (venous and arterial anastomoses performed) and hemodynamic stabilization, ICG was injected intravenously as a bolus in central vein catheter then flushed with $10 \mathrm{~mL}$ of sterile water. The Fluobeam ${ }^{\circledR}$ fixed on the Fluopod ${ }^{\mathrm{TM}}$ was placed 25 $\mathrm{cm}$ above the graft. Fluorescent signals were visualized in real-time, and images were recorded for around 3 minutes. With this short duration, only the consequences of hemodynamics features (arterial and portal perfusions, outflow and portosystemic shunts) and hepatic uptake could be analysed, whereas biliary excretion could not be studied (13)(21). The camera exposure time was set at $83 \mathrm{~ms}$ for all patients.

Postoperatively, adjustment process of images was completed, the $\mathrm{FI}$ of the region of interest (ROI) on the graft was quantified using the ImageJ software. The ROI was determined on the right lobe of liver. The mean value of the measured pixel intensities in the ROI for each image was calculated. In case of a heterogenous signal, the ROI was taken at the area of maximum FI. A moving average for smoothing the values was used to obtain the curve of the temporal course of the FI. To analyse the level of intensity, the initial value of the FI in the graft before ICG injection was subtracted from each post-injection intensity value to remove the background signal (22).

\section{Modelling of the Fluorescence Intensity Curve}

To avoid bias between the ICG injection and the start of recording $t_{\text {record }}$, only the measurements starting from the time $t_{\text {init }}$ such that $\mathrm{FI}_{\text {Liver,Obs }}\left(\mathrm{t}_{\text {init }}\right) \geq \mathrm{FI}_{\text {Liver,Obs }}\left(\mathrm{t}_{\text {record }}\right)+5$ Grayscales were taken into consideration. Thus, time zero in the model corresponds to $t_{\text {init }}$ of the recorded signal. Assessment of the temporal course of the $\mathrm{FI}$ was performed using an exponential model. The shape of the curves, increasing to reach a near plateau with a limit value, suggested that the simplest fit was:

$$
F I_{\text {Liver, } \text { fit }}(t)=C-B e^{-a t}
$$

Where $\mathrm{C}$ was the limit value, $\mathrm{C}-\mathrm{B}$ the initial value, $\mathrm{t}$ the time and $a$ the convergence rate (seconds ${ }^{-1}$ ).

The parameter a represented the speed of the fluorescent signal to reach the plateau phase (Figure 1): the higher the parameter $a$ is, the faster the plateau is reached. The 3 parameters of this model were calculated with a non-linear least-square fitting the measured FI values, using the Levenberg-Marquardt algorithm. Moreover, these 3 parameters were calculated by restricting all the recordings to 150 seconds after $t_{\text {init }}$ (parameter $a_{150}$ ), to eliminate variability in the total measurement time between patients. 


\section{Perioperative Data and Short-Term Postoperative Management}

Preoperative and intraoperative data recorded included patient's age and gender, donor's age, patient's and donor's body mass index (BMI), weight and type of graft, graft macrosteatosis, ischemia time, operative time, blood loss and transfusions rates. Postoperative data recorded were the occurrence and indication of a re-LT within 3 months. Follow-up was halted at POD 90. Until POD 7, close clinical monitoring, blood tests and doppler sonography were daily performed. A computed tomography scan was routinely performed between POD 7 and 10 (23). All patients received a standard triple immunosuppressive regimen that included corticosteroids, mycophenolate mofetil and tacrolimus. Indication of re-LT was always decided during a multidisciplinary meeting. In this study, quantitative analysis of graft fluorescence was not integrated into our decision-making process.

\section{Definitions}

The primary endpoint was the graft survival at 3 months, defined as the occurrence or not of a re$\mathrm{LT}$ (group re- $\mathrm{LT}^{+}$versus group re-LT- respectively) within 3 months after $\mathrm{LT}$, whatever the indication of re-LT (intention-to-treat analysis). This definition included patients who were listed for re-LT within 3 months and not transplanted during that period of time. In case of death before POD 90 from an extrahepatic cause, the patient was put in the group re-LT- $(n=1)$. Survival analysis was limited to 3 months in order to focus only on early graft function, and to minimize the contribution of subsequent causes of graft loss such as chronic rejection or recurrence of disease.

The secondary endpoint was the PNF, defined as a nonlife-sustaining graft leading to re-LT or death within POD 10 (5)(8).

\section{Statistical Analysis}

Quantitative variables were expressed as median [range], and qualitative variables as number (percentages). The Mann-Whitney $U$ test was used for continuous variables, and the Chi-square test for categorical variables. Univariate and multivariate risk factor analyses were performed using logistic regression test including all the preoperative, intraoperative, early postoperative (before POD 1) characteristics and donor's features, potentially related to the primary endpoint. The criteria defined by Olthoff et al. (4) were not included because they were considered as late (one week). Variables with a p-value $<0.1$ in univariate analysis were included in multivariate analysis. 
Receiver operating characteristics (ROC) and the area under the curve (AUC) with its 95\% confidence interval $\left(\mathrm{Cl}_{95 \%}\right)$ and $\mathrm{p}$ value were used to determine the best diagnostic value of the parameter $a_{150}$ to predict graft survival at 3 months and PNF. The predictive power of the parameter $a_{150}$ was characterized by its sensitivity (Se), specificity (Spe), Youden index, and positive and negative likelihood ratios (LR+ and LR- respectively).

Statistical analyses were performed using SPSS 23 software (SPSS Inc, Chicago, IL, United States). A p-value $\leq 0.05$ was considered statistically significant. 


\section{RESULTS}

\section{Patients}

From July 2017 to May 2019, 76 LTs performed in 72 patients were included in this study. A comparison of the preoperative, intraoperative, early postoperative data and donor's characteristics did not reveal any imbalance between the 2 groups (group re-LT- versus group re$\mathrm{LT}^{+}$) (Table 1), except for cold ischemia, which was longer in the group re-LT+ ${ }^{+} 576$ minutes [380640] versus 410 minutes [225-734], $p=0.047$ ), and for graft macrosteatosis $>30 \%$, more frequent in the group re-LT+ $(16.7 \%$ versus $1.5 \%, p=0.03)$. Of these $76 \mathrm{LTs}, 11(14.5 \%)$ underwent a retransplantation. Only 2 patients $(2.6 \%)$ received a partial graft (right splits), and 2 domino LTs were performed. All other patients $(n=72,94.7 \%)$ were transplanted with whole grafts.

Primary liver disease features are summarized in Table 1. The main primary liver disease was cirrhosis in 55 patients $(72.4 \%)$, including 32 patients (42.1\%) transplanted for advanced cirrhosis (included all the complications of cirrhosis such as hepatic failure, portal hypertension, refractory ascites, digestive bleeding), and 23 patients (30.3\%) for hepatocellular carcinoma. The causes of cirrhosis were alcohol for 25 patients (45.5\%), hepatitis B and C virus for 9 (16.4\%), secondary biliary cirrhosis for $6(10.9 \%)$, non-alcoholic steato-hepatitis for $5(9.1 \%)$, mixed cirrhosis (alcohol and NASH) for 4 (7.3\%), primary biliary cirrhosis for 3 (5.4\%) and cryptogenic for $3(5.4 \%)$.

Postoperatively, PNF occurred in 4 patients (5.3\%) and EAD in 31 patients (40.8\%). All patients with PNF were re-transplanted in emergency (median time: 3 days [2-6]). Among those with EAD, 5 patients (16\%) were re-transplanted within 3 months.

\section{Analysis of Temporal Curve of Fluorescence Intensity}

No adverse events or side effects related to the ICG injection were observed intraoperatively or during follow-up. A video recording is presented as an example in the supplementary data (ICG injection at 6 seconds). The mean $\mathrm{FI}$ of all grafts at some characteristic times after ICG injection is shown in Figure 2. First, the FI in the graft increased rapidly after ICG injection, corresponding to the hepatic perfusion phase (arterial and portal perfusion). Then, the increase was more gradual, corresponding to the hepatic uptake phase of ICG, until reaching a near-plateau at around 120 seconds. The decrease of the FI was not recorded in this study.

\section{Graft Survival at 3 Months}

Two patients died within the first 3 months: one from a cardiogenic shock in immediate postoperative course, without retransplantation (group re-LT-) and one after re-transplantation at POD 3 (death occurring at one month from multiorgan failure, mesenteric ischemia). 
Six patients $(7.9 \%)$ were re-transplanted within the 3 months after LT, for PNF $(n=4)$, hepatic artery thrombosis $(n=1)$, or ischemic cholangitis $(n=1$, patent artery) complicated by ascending cholangitis. The median time to liver re-transplantation was 3 days [1-68]. All the patients listed for a re-LT within 3 months were re-transplanted within 3 months.

No differences were found between both groups concerning the level of $\mathrm{Fl}$, whatever the time of analysis. The parameter $a_{150}$ was however significantly higher in the group re-LT+ compared to the group re-LT- group: $0.022 \mathrm{~s}^{-1}$ [0.011-0.059] versus $0.012 \mathrm{~s}^{-1}$ [0.0001-0.054] respectively, $p=0.01$ (Figure $3 A$ ). For the parameters $B$ and $C$, there were no differences between the 2 groups $(p=0.20$ and $p=0.59$ respectively).

In univariate analysis, the predictors of re-LT within 3 months were the parameter $a_{150}(O R=2.15$; $\mathrm{Cl}_{95 \%}$ [1.18-3.91]; $\left.\mathrm{p}=0.01\right)$, the operative time $\left(\mathrm{OR}=1.01 ; \mathrm{Cl}_{95 \%}[1-1.02] ; \mathrm{p}=0.03\right)$ and transfused red blood cells units $\left(\mathrm{OR}=1.22 ; \mathrm{Cl}_{95 \%}\right.$ [1.04-1.42]; $\left.\mathrm{p}=0.01\right)$. Under multivariate analysis, the parameter $a_{150}$ was the only independent risk factor (OR=2.4; $\mathrm{Cl}_{95 \%}[1.05-5.5] ; \mathrm{p}=0.04$ ) (Table 2).

The parameter $a_{150} \geq 0.0155 \mathrm{~s}^{-1}$ predicted the risk of re-LT within 3 months with a sensitivity of $83.3 \%$, a specificity of $78.6 \%$, a likelihood ratio of a positive test of 3.89 and a likelihood ratio of a negative test of 0.21 . The AUC was 0.82 [0.67-0.98], $\mathrm{p}=0.01$ (Figure 3B).

\section{Primary Non-Function}

PNF occurred in 4/76 LTs (5.3\%). The parameter $a_{150}$ was significantly higher in case of PNF, compared to the control group: $0.027 \mathrm{~s}^{-1}[0.011-0.059]$ versus $0.012 \mathrm{~s}^{-1}$ [0.0001-0.054] respectively, $p=0.04$ (Figure $4 A$ ). Similarly, no differences were found between the 2 groups concerning the parameters $\mathrm{B}$ and $\mathrm{C}$, and the level of $\mathrm{FI}$.

In univariate analysis, the risk factor for the occurrence of a PNF were the parameter $a_{150}$ $\left(\mathrm{OR}=2.32 ; \mathrm{Cl}_{95 \%}\right.$ [1.2-4.5]; $\left.\mathrm{p}=0.01\right)$, the recipient BMI (OR=1.17; $\mathrm{Cl}_{95 \%}$ [1-1.37]; $\left.\mathrm{p}=0.047\right)$, the operative time $\left(\mathrm{OR}=1.01 ; \mathrm{Cl}_{95 \%}[1-1.02] ; \mathrm{p}=0.03\right)$, transfused red blood cells units $(\mathrm{OR}=1.24$; $\mathrm{Cl}_{95 \%}$ [1.04-1.48]; $p=0.02$ ), and arterial lactate concentration at the end of $\mathrm{LT} \geq 5 \mathrm{mmol} / \mathrm{L}$ (LCEOT) $\left(\mathrm{OR}=13.15 ; \mathrm{Cl}_{95 \%}[1.27-136.8] ; \mathrm{p}=0.02\right)$ (Table 3). Multivariate analysis was not performed due to the very small number of events.

A ROC curve was also used to quantify the predictive strength of the parameter $a_{150}$. The AUC was 0.81 [0.58-1], $p=0.04$. Parameter $a_{150} \geq 0.0178 \mathrm{~s}^{-1}$ predicted the risk of PNF with a sensitivity of $75 \%$, a specificity of $81.9 \%$, a likelihood ratio of a positive test of 4.14 and a likelihood ratio of a negative test of 0.31 (Figure $4 B$ ). 


\section{DISCUSSION}

\section{Statement of Principal Findings}

This pilot study was carried out on the basis of a prospective cohort of 76 non-consecutive LT, of which 6 patients were re-transplanted. The tolerability and safety of ICG injection during LT was excellent. We demonstrated the feasibility of the quantitative analysis of the ICG fluorescence during LT to evaluate the graft function and to predict its survival. The choice of the exponential model made it possible to fit the measured FI curve with the simulated one (mathematical model) and to define three patient-specific parameters. Among them, the parameter $a_{150}$ representing the temporal evolution indicator of the $\mathrm{FI}$, predicted graft survival at 3 months and PNF with satisfactory accuracy.

These results, parameter $a_{150}$ being significantly higher in the re-LT+ and PNF groups, appeared paradoxical at first because we expected to have a faster increase in $\mathrm{Fl}$ in the control group (higher parameter $a_{150}$ ). With this short delay of recording, the $\mathrm{FI}$ curve increased first rapidly (perfusion phase) and then more gradually (hepatic uptake phase) to reach a near-plateau (Figure 2). The parameter $a_{150}$ represented the rate of the fluorescent signal to reach this plateau (Figure 1). To explain that the plateau was reached more quickly in the event of re-LT within 3 months or PNF, we hypothesized a faster saturation of the hepatic uptake of ICG. To our knowledge, there is no previous report to validate or not this hypothesis. A future study will be performed to explore this hypothesis.

\section{Interpretation with Reference to Other Studies}

Quantitative assessment of the global hepatic function using this imaging technique was only reported by Narasaki et al. (13). They reported that the FI on the liver surface was not correlated with the global hepatic function measured by ICG plasmatic clearance (ICGK) at $15 \mathrm{~min}$. This lack of correlation resulted from an inter-individual variability in factors that can influence $\mathrm{FI}$ by absorption and scattering of near-infrared fluorescent light, such as the presence of liver steatosis or fibrosis. Our results were similar concerning the analysis of $\mathrm{FI}$.

Narasaki et al. (13) developed a mathematical model to fit the measured FI curve but only from 3 points (at 1, 5 and 15 minutes), whereas our exponential model used all the points of this measured curve to fit it. From their model, they also calculated a parameter representing the temporal evolution of the $\mathrm{FI}$, but negatively correlated to the parameter $a_{150}$. While they found a significant correlation between the temporal evolution of $\mathrm{FI}$ and the ICGK but with a mild correlation coefficient $(r=0.57)$, our results were opposed to theirs. Many differences between the 2 studies could contribute to these contradictory results: measurements performed on a "healthy" 
liver before hepatic resection for Narasaki et al., while our measurements were performed on graft after LT after immediate revascularisation; about primary endpoints to assess liver function (ICGK versus graft survival, respectively); a shorter signal acquisition in our study (150 seconds) because an acquisition time of 15 minutes was incompatible with surgical requirements; the ICG dose was much higher in their study $(2.5 \mathrm{mg} / \mathrm{L}$ of liver volume, or about $2.75 \mathrm{mg}$ per patient for a median liver volume of $1.1 \mathrm{~L})$ than in our method $(0.01 \mathrm{mg} / \mathrm{kg}$ body weight, or about $0.72 \mathrm{mg}$ per patient for a mean weight of $72 \mathrm{~kg}$ ); and finally, the study population was larger in our study (76 LT versus 16 patients).

Many predictive factors of graft survival are recognized in the literature (6)(7). The main predictors of PNF and/or graft survival are summarized in Table 4. EAD defined by the biological abnormalities during the first seven day following $L T$, according to the criteria by Olthoff et al. (4), are the most consensual. These criteria are predictive of the graft survival at 6 months. However, most of the predictors are too late since they may require about one week to be quantified. Up to now, only very few early predictive factors are reported. The theoretical advantage of such early predictive factors is that the patient could be re-transplanted quickly if necessary, in order to decrease mortality (9)(24).

Golse et al. (5) showed that LCEOT $\geq 5 \mathrm{mmol} / \mathrm{L}$ was an early predictive factor of PNF. LCEOT and parameter $a_{150}$, both early predictors of PNF with each of them a satisfactory accuracy, could be associated to improve the prediction of PNF in order to better select the patients requiring retransplantation. Indeed, although the multivariate analysis could not be performed, these two predictive factors were not correlated (Spearman correlation $r=0.07 ; p=0.57$ ). Further studies should be carried out to assess the diagnostic performance of this association.

To our knowledge, the qualitative analysis of the fluorescence patterns after ICG injection (8) was the only intraoperative predictive factor to predict the PGD. However, as already mentioned, qualitative analysis is subjective and operator-dependent. Moreover, this endpoint is questionable because it is less clinically relevant than graft survival. The parameter $a_{150}$ is consequently the only intraoperative predictive factor of PNF and graft survival at 3 months with a very good accuracy. Although the comparison is difficult because each of these predictors used a different primary endpoint, the parameter $a_{150}$ had a very good sensitivity and specificity to predict both PNF and graft survival at 3 months, with the highest AUC.

The incidence of PGD and PNF in our series were $40.8 \%$ and $5.3 \%$ respectively, which is slightly higher than the overall incidence in the literature $(4)(6)(7)$, probably explained by the more frequent use of marginal graft in our center (1)(2). The parameter $a_{150}$ was the only independent predictive factor of graft survival whereas well-known risk factors (cold ischemia time, graft 
macrosteatosis $>30 \%$...) (4)(5)(6)(7) were not significant (due to a small number of patients included). This suggests that parameter $a_{150}$ may be more sensitive than the well-known risk factors.

\section{Strengths and Weaknesses of the Study}

Graft survival was a clinically relevant endpoint, which can be considered as a gold standard (4). Overall survival was not chosen as endpoint because it depends on many other factors, sometimes independent of the intrinsic quality of the graft and not evaluable by ICG fluorescence imaging. The 3-month delay was chosen to limit the impact of later causes of graft loss such as rejection or recurrence of the initial disease (4). The early intraoperative prediction of PNF was also clinically very relevant to identify as soon as possible patients needing a re-transplantation in emergency (24).

This exponential model has the advantage of fitting the measured FI curve with greater accuracy than the model of Narasaki et al. (13). The restriction of recording to 150 seconds allowed the values obtained to be homogenized and gave the same weight to the beginning of the fluorescent curve for all videos. Moreover, a short acquisition duration was a minimal extra-time compared to the operative time, making it more easily acceptable to the surgical team and safe for the patient. The parameter $a_{150}$ can be obtained in real time during LT thanks to the development of a computer program that automatically performs adjustment process, quantification of $\mathrm{FI}$ and multiparametric modelling.

One limitation of our study was the low number of LT included, with only 6 events in the group re$\mathrm{LT}^{+}$and 4 in the PNF group. If the feasibility of this imaging technique has been demonstrated, further studies are now needed to validate these preliminary results.

Despite the good predictive accuracy of our model, its clinical adoption needs to be assessed for two reasons. First, this parameter was measured for only a few seconds during LT, and the consequence of some possible biases such as hemodynamic instability or the possible effects of anesthetic agents during general anesthesia are not yet known on the pharmacokinetics of ICG (13). For this reason, all measurements were performed on hemodynamically stable patients (pressor amines permitted) because severe instability, being itself a risk factor for PNF, could bias ICG interpretation. Second, the indication for re-LT is a serious decision with severe consequences for the patient with higher morbidity and mortality (9)(24). The parameter $a_{150}$ alone cannot therefore influence the decision to re-transplant in emergency, but it is nevertheless an additional argument associated with the usual criteria for retaining the indication of re-LT in emergency. Because of its high negative predictive value $(98.2 \%)$, the parameter $a_{150}$ could simplify the intensive postoperative monitoring in some patients for early rehabilitation. This 
imaging technique could also be tested during normothermic preservation on machine to evaluate ex-vivo the hepatocellular function with standardized liver perfusion, and thus better select transplantable grafts ( $a_{150}$ cutoff to be defined) (25).

ICGK is an accurate test to assess liver dysfunction in the early postoperative period. However, most liver transplant units do not use ICG clearance because it lacks the ability to differentiate the underlying causes (PNF, acute rejection, sepsis, hepatic artery thrombosis...) (26). ICG fluorescence depends on liver perfusion and hepatocellular function, and is unaffected by these causes involved in ICG metabolism after LT. Unlike ICG clearance, which is performed postoperatively, intraoperative ICG fluorescence quantification can lead to an intraoperative modification of the surgical strategy (modulation of the portal flow...) (27).

In the future, with a longer recording time, multi-compartmental modelling of ICG transport in the liver, based on the mathematical model previously developed by Audebert and Vignon-Clementel (21), could provide a better understanding of the physiology of ICG fluorescence dynamics in the liver in order to evaluate its liver function and its pathophysiology according to the compartment affected (systemic blood circulation, hepatic sinusoid, hepatocyte or bile duct).

Beyond the clinical involvement, understanding the ICG fluorescence dynamics during the early phases of hepatic perfusion and uptake can allow the acquired knowledge to be transposed to less invasive molecular medical imaging techniques, such as ${ }^{99} \mathrm{Tc}-M e b r o f e n i n$ scintigraphy, because transporters involved in the hepatic uptake of 99mTc-mebrofenin and ICG are the same (28).

\section{CONCLUSION}


Quantitative analysis of indocyanine green fluorescence imaging during liver transplantation is feasible. The analysis of the temporal evolution of the fluorescent signal by calculating the parameter $a_{150}$ thanks to a multi-parametric modelling of the observed fluorescence intensity curve, offers the advantage of an immediate snapshot of liver function and the possibility to predict graft survival at 3 months and the occurrence of PNF with a high accuracy. This reliable intraoperative predictor could be an additional argument for clinicians to take a rapid decision on whether to re-transplant a patient with PNF, although this choice remains a multiparametric matter. Measurement of the parameter $a_{150}$ represents a supplementary tool in the entire array of diagnostic tests available to clinicians and may become part of daily practice by all transplant teams. Further studies with larger cohort should confirm these results and determine the best decisional impact and clinical benefit of this imaging technique. At the microscopic level, understanding the pharmacodynamics of ICG will allow a better interpretation of the fluorescence curve. 


\section{REFERENCES}

1. Giretti G, Barbier L, Bucur P, Marques F, Perarnau J-M, Ferrandière M, et al. Recipient Selection for Optimal Utilization of Discarded Grafts in Liver Transplantation. Transplantation 2018;102(5):775-82.

2. Nemes B, Gámán G, Polak WG, Gelley F, Hara T, Ono S, et al. Extended-criteria donors in liver transplantation Part II: reviewing the impact of extended-criteria donors on the complications and outcomes of liver transplantation. Expert Rev Gastroenterol Hepatol 2016;10(7):841-59.

3. Barshes NR, Horwitz IB, Franzini L, Vierling JM, Goss JA. Waitlist Mortality Decreases with Increased Use of Extended Criteria Donor Liver Grafts at Adult Liver Transplant Centers. Am J Transplant 2007;7(5):1265-70.

4. Olthoff KM, Kulik L, Samstein B, Kaminski M, Abecassis M, Emond J, et al. Validation of a current definition of early allograft dysfunction in liver transplant recipients and analysis of risk factors. Liver Transpl 2010;16(8):943-9.

5. Golse N, Guglielmo N, El Metni A, Frosio F, Cosse C, Naili S, et al. Arterial Lactate Concentration at the End of Liver Transplantation Is an Early Predictor of Primary Graft Dysfunction. Ann Surg 2019;270(1):131-8.

6. Chen X-B, Xu M-Q. Primary graft dysfunction after liver transplantation. Hepatobiliary Pancreat Dis Int 2014;13(2):125-37.

7. Bolondi G, Mocchegiani F, Montalti R, Nicolini D, Vivarelli M, De Pietri L. Predictive factors of short term outcome after liver transplantation: A review. World J Gastroenterol 2016;22(26):5936-49.

8. Figueroa R, Golse N, Alvarez FA, Ciacio O, Pittau G, Sa Cunha A, et al. Indocyanine green fluorescence imaging to evaluate graft perfusion during liver transplantation. HPB 2019;21(4):387-392.

9. Uemura T, Randall HB, Sanchez EQ, Ikegami T, Narasimhan G, McKenna GJ, et al. Liver retransplantation for primary nonfunction: analysis of a 20-year single-center experience. Liver Transplant 2007;13(2):227-33. 
10. Lim C, Vibert E, Azoulay D, Salloum C, Ishizawa T, Yoshioka R, et al. Indocyanine green fluorescence imaging in the surgical management of liver cancers: current facts and future implications. J Visc Surg 2014;151(2):117-24.

11. Imamura H, Sano K, Sugawara Y, Kokudo N, Makuuchi M. Assessment of hepatic reserve for indication of hepatic resection: decision tree incorporating indocyanine green test. $J$ Hepatobiliary Pancreat Surg 2005;12(1):16-22.

12. Kawaguchi $\mathrm{Y}$, Akamatsu N, Ishizawa T, Kaneko J, Arita J, Sakamoto Y, et al. Evaluation of hepatic perfusion in the liver graft using fluorescence imaging with indocyanine green. Int $J$ Surg Case Rep 2015;14:149-51.

13. Narasaki H, Noji T, Wada H, Ebihara $Y$, Tsuchikawa T, Okamura K, et al. Intraoperative Real-Time Assessment of Liver Function with Near-Infrared Fluorescence Imaging. Eur Surg Res 2017;58(5-6):235-245.

14. Kawaguchi Y, Ishizawa T, Miyata Y, Yamashita S, Masuda K, Satou S, et al. Portal uptake function in veno-occlusive regions evaluated by real-time fluorescent imaging using indocyanine green. J Hepatol 2013;58(2):247-53.

15. Kawaguchi $\mathrm{Y}$, Nomura $\mathrm{Y}$, Nagai $\mathrm{M}$, Koike $\mathrm{D}$, Sakuraoka $\mathrm{Y}$, Ishida $\mathrm{T}$, et al. Liver transection using indocyanine green fluorescence imaging and hepatic vein clamping. $\mathrm{Br} \mathrm{J}$ Surg 2017;104(7):898-906.

16. Bismuth $H$, Chiche $L$, Adam R, Castaing D, Diamond T, Dennison A. Liver resection versus transplantation for hepatocellular carcinoma in cirrhotic patients. Ann Surg 1993;218(2):145-51.

17. Azoulay D, Bhangui P, Andreani P, Salloum C, Karam V, Hoti E, et al. Short- and Long-term Donor Morbidity in Right Lobe Living Donor Liver Transplantation: 91 Consecutive Cases in a European Center. Am J Transplant 2011;11(1):101-10.

18. Azoulay D, Castaing D, Adam R, Savier E, Delvart V, Karam V, et al. Split-liver transplantation for two adult recipients: feasibility and long-term outcomes. Ann Surg 2001;233(4):565-74. 
19. Azoulay D, Samuel D, Castaing D, Adam R, Adams D, Said G, et al. Domino liver transplants for metabolic disorders: experience with familial amyloidotic polyneuropathy. J Am Coll Surg 1999;189(6):584-93.

20. Gaffey MJ, Boyd JC, Traweek ST, Ali MA, Rezeig M, Caldwell SH, et al. Predictive value of intraoperative biopsies and liver function tests for preservation injury in orthotopic liver transplantation. Hepatol 1997;25(1):184-9.

21. Audebert C, Vignon-Clementel IE. Model and methods to assess hepatic function from indocyanine green fluorescence dynamical measurements of liver tissue. Eur J Pharm Sci 2018;115:304-319.

22. Detter C, Wipper S, Russ D, Iffland A, Burdorf L, Thein E, et al. Fluorescent cardiac imaging: a novel intraoperative method for quantitative assessment of myocardial perfusion during graded coronary artery stenosis. Circulation 2007;116(9):1007-14.

23. Memeo R, Ciacio O, Pittau G, Cherqui D, Castaing D, Adam R, et al. Systematic computer tomographic scans 7 days after liver transplantation surgery can lower rates of repeattransplantation due to arterial complications. Transplant Proc 2014;46(10):3536-42.

24. Pokorny H, Gruenberger T, Soliman T, Rockenschaub S, Längle F, Steininger R. Organ survival after primary dysfunction of liver grafts in clinical orthotopic liver transplantation. Transpl Int 2000;13 Suppl 1:S154-7.

25. Nasralla D, Coussios CC, Mergental H, Akhtar MZ, Butler AJ, Ceresa CDL, et al. A randomized trial of normothermic preservation in liver transplantation. Nature. 2018;557(7703):50-56.

26. Levesque E, Saliba F, Benhamida S, Ichaï P, Azoulay D, Adam R, et al. Plasma disappearance rate of indocyanine green: a tool to evaluate early graft outcome after liver transplantation. Liver Transplant 2009;15(10):1358-64.

27. Gomez Gavara C, Bhangui P, Salloum C, Osseis M, Esposito F, Moussallem T, et al. Ligation versus no ligation of spontaneous portosystemic shunts during liver transplantation: Audit of a prospective series of 66 consecutive patients. Liver Transplant 2018;24(4):505-515. 
28. de Graaf W, Häusler S, Heger M, van Ginhoven TM, van Cappellen G, Bennink RJ, et al. Transporters involved in the hepatic uptake of $(99 \mathrm{~m})$ Tc-mebrofenin and indocyanine green. J Hepatol 2011;54(4):738-45. 


\begin{tabular}{|c|c|c|c|}
\hline Perioperative features & $\begin{array}{c}\text { Group Re-LT } \\
\quad(n=70)\end{array}$ & $\begin{array}{c}\text { Group Re-LT } \\
\qquad(\mathrm{n}=6)\end{array}$ & p \\
\hline Sex F/M (\%) & $38.6 / 61.4$ & $33.3 / 66.7$ & 0.80 \\
\hline Age at LT (years)* & $58.5[18-74]$ & $61.5[49-70]$ & 0.24 \\
\hline BMI $\left(\mathrm{kg} / \mathrm{m}^{2}\right)^{*}$ & 25 [15-43] & $26[21-41]$ & 0.35 \\
\hline MELD Score* & $19[6-40]$ & $17.5[13-29]$ & 0.94 \\
\hline Retransplantation (\%) & 15.7 & 0 & 0.29 \\
\hline Partial graft (\%) & 2.9 & 0 & 0.68 \\
\hline \multicolumn{4}{|l|}{ Main indication of LT (\%) } \\
\hline - Advanced cirrhosis & 40 & 66.7 & \multirow{9}{*}{0.82} \\
\hline - Hepatocellular carcinoma & 31.4 & 16.7 & \\
\hline - Fulminant hepatic failure & 5.7 & 0 & \\
\hline - Primary non-function & 4.3 & 0 & \\
\hline - PSC & 4.3 & 0 & \\
\hline - FAP & 4.3 & 0 & \\
\hline - Chronic rejection & 2.9 & 0 & \\
\hline - Ischemic cholangitis & 2.9 & 0 & \\
\hline - Other & 4.3 & 16.7 & \\
\hline Donor's age (years) ${ }^{*}$ & 55 [11-90] & $69[13-77]$ & 0.76 \\
\hline Donor's BMI $\left(\mathrm{kg} / \mathrm{m}^{2}\right)^{*}$ & $25[16-38]$ & 26 [15-36] & 0.98 \\
\hline Cold ischemia time $(\mathrm{min})^{\star}$ & 410 [225-734] & 576 [380-640] & 0.047 \\
\hline RBC units* & $2.5[0-15]$ & $6.5[0-26]$ & 0.10 \\
\hline Graft weight $(\mathrm{g})^{*}$ & $1288[320-2400]$ & 1320 [700-2200] & 0.98 \\
\hline Operative time $(\mathrm{min})^{*}$ & 411 [287-725] & 508 [363-828] & 0.09 \\
\hline Graft macrosteatosis $>30 \%(\%)$ & 1.5 & 16.7 & 0.03 \\
\hline LCEOT $\geq 5 \mathrm{mmol} / \mathrm{L}(\%)$ & 19.1 & 50 & 0.08 \\
\hline \multicolumn{4}{|c|}{ Table 1: Perioperative features and donors characteristics. } \\
\hline \multicolumn{4}{|c|}{$\begin{array}{l}{ }^{*} \text { Median [range] } \\
\text { BMI: body mass index; F: female; FAP: familial amyloid polyneuropathy; LCEOT: lactate concentration at the end } \\
\text { of liver transplantation; LT: liver transplantation; M: male; MELD: model for end-stage liver disease; PSC: primary } \\
\text { sclerosing cholangitis; RBC: red blood cells. Advanced cirrhosis included all the complications of cirrhosis such } \\
\text { as hepatic failure, portal hypertension, refractory ascites, digestive bleeding except hepatocellular carcinoma. }\end{array}$} \\
\hline
\end{tabular}

Table 2: Logistic regression analysis for predictors of graft survival at 3 months.

Univariable Analysis

Variables

Recipient sex F/M
OR $95 \%$ Cl

p

OR $95 \% \mathrm{Cl}$
Multivariable Analysis

p 


\begin{tabular}{lcccc} 
Recipient age (years) & $1.04[0.95-1.14]$ & 0.36 & - & - \\
Recipient BMI $\left(\mathrm{kg} / \mathrm{m}^{2}\right)$ & $1.10[0.96-1.26]$ & 0.19 & - & - \\
MELD score & $0.99[0.91-1.08]$ & 0.88 & - & - \\
\hline Donor age (year) & $1.01[0.97-1.05]$ & 0.70 & - & - \\
\hline Donor BMI $\left(\mathrm{kg} / \mathrm{m}^{2}\right)$ & $1[0.84-1.20]$ & 0.97 & - & - \\
\hline Cold ischemia time $(\mathrm{min})$ & $1.01[1-1.01]$ & 0.05 & $1.01[1-1.02]$ & 0.11 \\
Operative time $(\mathrm{min})$ & $1[1-1,02]$ & 0.03 & $1[0.99-1.02]$ & 0.51 \\
Number of transfused RBC & $1.22[1.04-1.42]$ & 0.01 & $1.12[0.89-1.41]$ & 0.35 \\
units & & & & - \\
Graft weight $(\mathrm{g})$ & $1[0.99-1.01]$ & 0.77 & & - \\
LCEOT >5mmol/L & $4.23[0.77-23.41]$ & 0.10 & $2.12[0.20-22.33]$ & 0.53 \\
Graft macrosteatosis $\geq 30 \%$ & $6.4[0.49-83.4]$ & 0.16 & - & - \\
Parameter $a_{150}\left(\mathrm{~s}^{-1}\right)$ & $2.15[1.18-3.91]$ & 0.01 & $2.4[1.05-5.50]$ & 0.04 \\
\hline
\end{tabular}

BMI: body mass index; F: female; LCEOT: lactate concentration at the end of liver transplantation; LT: liver transplantation; M: male; MELD: model for end-stage liver disease; RBC: red blood cells.

Table 3: Logistic regression analysis for predictors of primary non-function.

\section{Univariable Analysis}

\begin{tabular}{lccc}
\cline { 2 - 3 } \multicolumn{1}{c}{ Variables } & OR & 95\% Cl & P \\
Recipient sex F/M & 1.67 & {$[0.22-12.53]$} & 0.62 \\
Recipient age (years) & 1.01 & {$[0.92-1.1]$} & 0.87 \\
Recipient BMI $\left(\mathrm{kg} / \mathrm{m}^{2}\right)$ & 1.17 & {$[1-1.37]$} & 0.047 \\
MELD score & 0.98 & {$[0.89-1.09]$} & 0.76 \\
Donor age (years) & 1.05 & {$[0.98-1.13]$} & 0.14 \\
Donor BMI $\left(\mathrm{kg} / \mathrm{m}^{2}\right)$ & 1.10 & {$[0.9-1.35]$} & 0.35 \\
Cold ischemia time $(\mathrm{min})$ & 1.01 & {$[0.99-1.02]$} & 0.07
\end{tabular}


Operative time (min)

Number of transfused RBC

units

Graft weight (g) 1

LCEOT > $5 \mathrm{mmol} / \mathrm{I}$

13.15

[0.99-1.01]

0.51

Graft macrosteatosis $\geq 30 \%$

[1.27-136.82]

0.03

Parameter $\mathrm{a}_{150}\left(\mathrm{~s}^{-1}\right)$

2.32

[0.76-158]

0.08

\section{Parameter $a_{150}\left(s^{-1}\right)$}

[1.2-4.5]

0.01

BMI: body mass index; F: female; LCEOT: lactate concentration at the end of liver transplantation; LT: liver transplantation; M: male; MELD: model for end-stage liver disease; RBC: red blood cells.

Multivariable analysis was not possible due to the very small number of events ( $n=4$ PNF). 
Table 4: Review of the main predictors of graft survival.

$\begin{array}{ccccccc}\text { Predictors } & \begin{array}{c}\text { Number of } \\ \text { patients }\end{array} & \text { Endpoints } & \text { Sensitivity } & \text { Specificity } & \text { LR }+\quad \text { LR }- & \text { AUC } \\ {[95 \% \mathrm{Cl}]} & \mathbf{p}\end{array}$

Olthoff and al. criteria ${ }^{(4)}$ :

- $\quad$ Bilirubin $\geq 10 \mathrm{mg} / \mathrm{dL}$ on

\begin{tabular}{|c|c|c|c|c|c|c|c|}
\hline POD 7 & 297 & Graft survival & $69.2 \%$ & $81.2 \%$ & 3.68 & 0.38 & 0.75 \\
\hline INR $\geq 1.6$ on POD 7 & & at 6 months & & & & & - \\
\hline
\end{tabular}

- $\quad$ ALAT or ASAT $\geq 2000 U I / L$ within POD 7

\section{LCEOT $^{(5)}$ :}

- $\quad \geq 5 \mathrm{mmol} / \mathrm{L}$

296

PNF

$83.3 \%$

$74.3 \%$

3.65

0.25

0.75

0.045

[0.55-0.93]

Fluorescence types ${ }^{(8)}$ :

- Type 1: Homogeneous

PGD

$57.9 \%$

$78.5 \%$

2.69

0.54

0.72

[0.59-0.86]

areas

- Type 3: Non-homogeneous

\section{Parameter $\mathbf{a}_{150}$ :}

- $\quad \geq 0.0155 \mathrm{~s}^{-1}$

76 Graft survival

$83.3 \% \quad 78.6 \%$

3.89

0.21

0.82

at 3 months

[0.55-0.93]

\subsection{1}




\section{Parameter $\mathbf{a}_{150}$ :}

- $\geq 0.0178 \mathrm{~s}^{-1}$

ALAT: alanine aminotransferase; ASAT: aspartate aminotransferase; AUC: area under the curve; Cl: confidence interval; INR: international normalized ratio; LCEOT: lactacte concentration at the end of LT; LR +: likelihood ratio positive; LR -: likelihood ratio negative; PGD: primary graft dysfunction (PNF and EAD according to Olthoff et al. ${ }^{(4)}$ ); PNF: primary non-function; POD: postoperative day. 
Figure 1

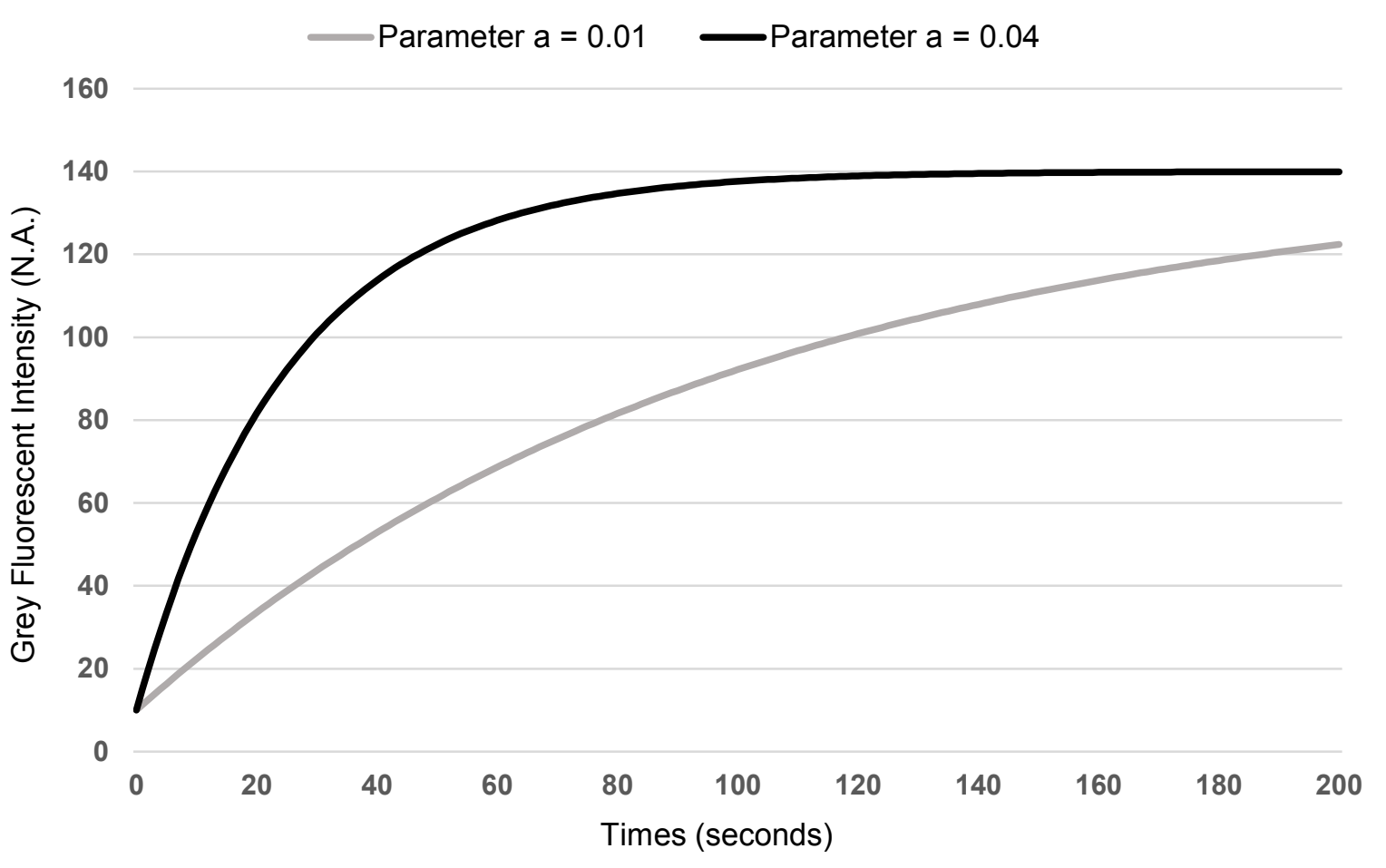


Figure 2

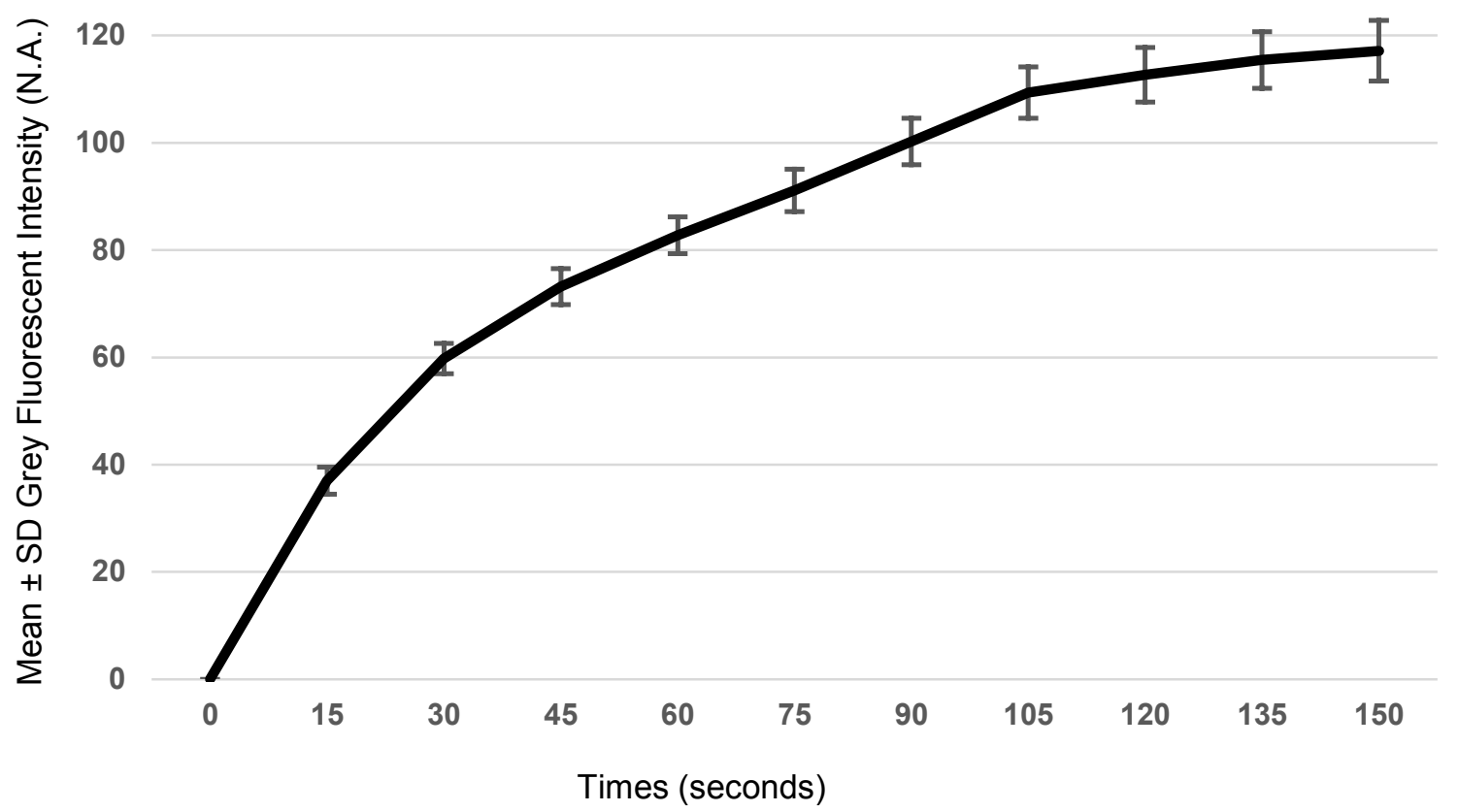


Figure 3
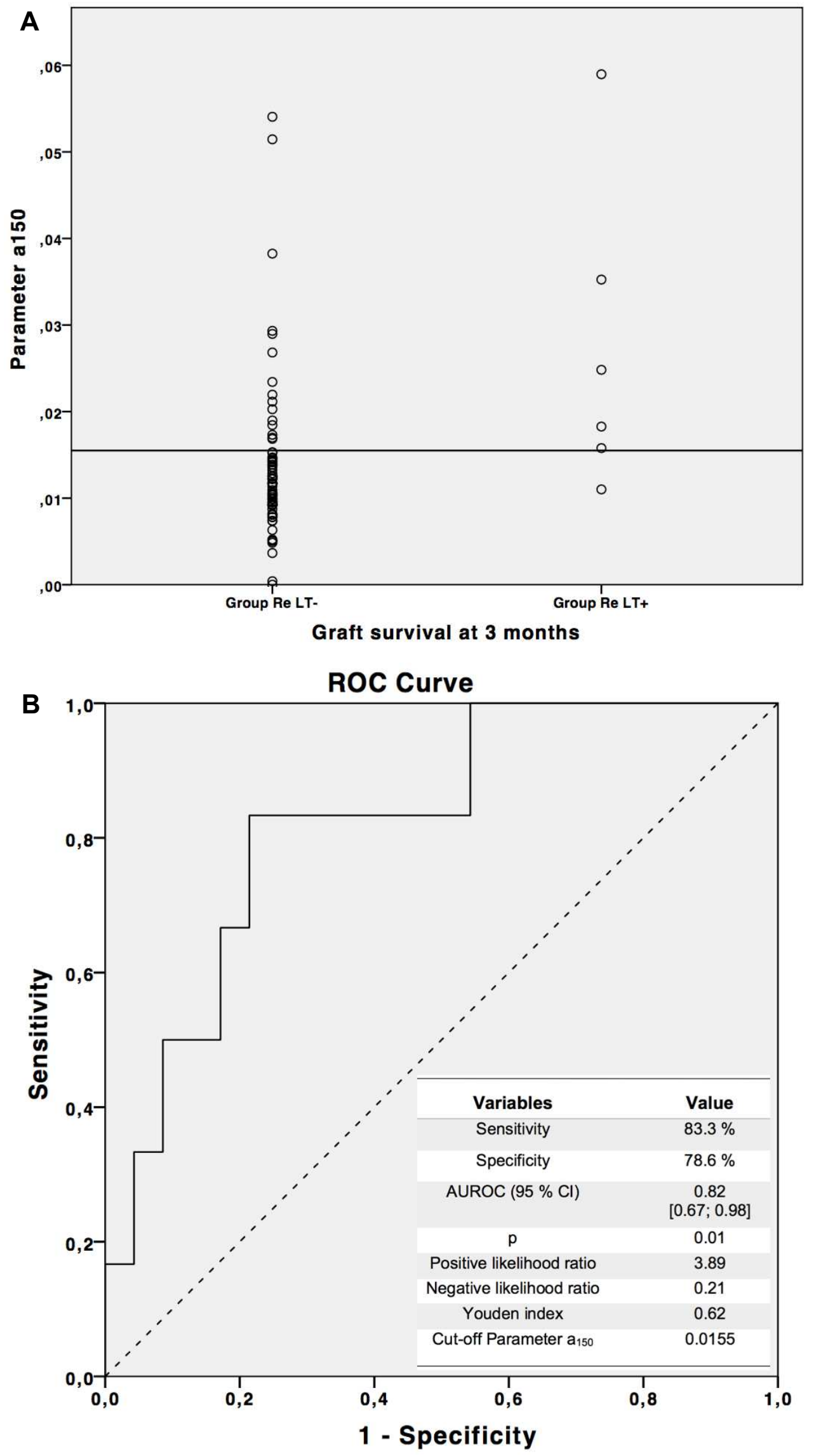
Figure 4
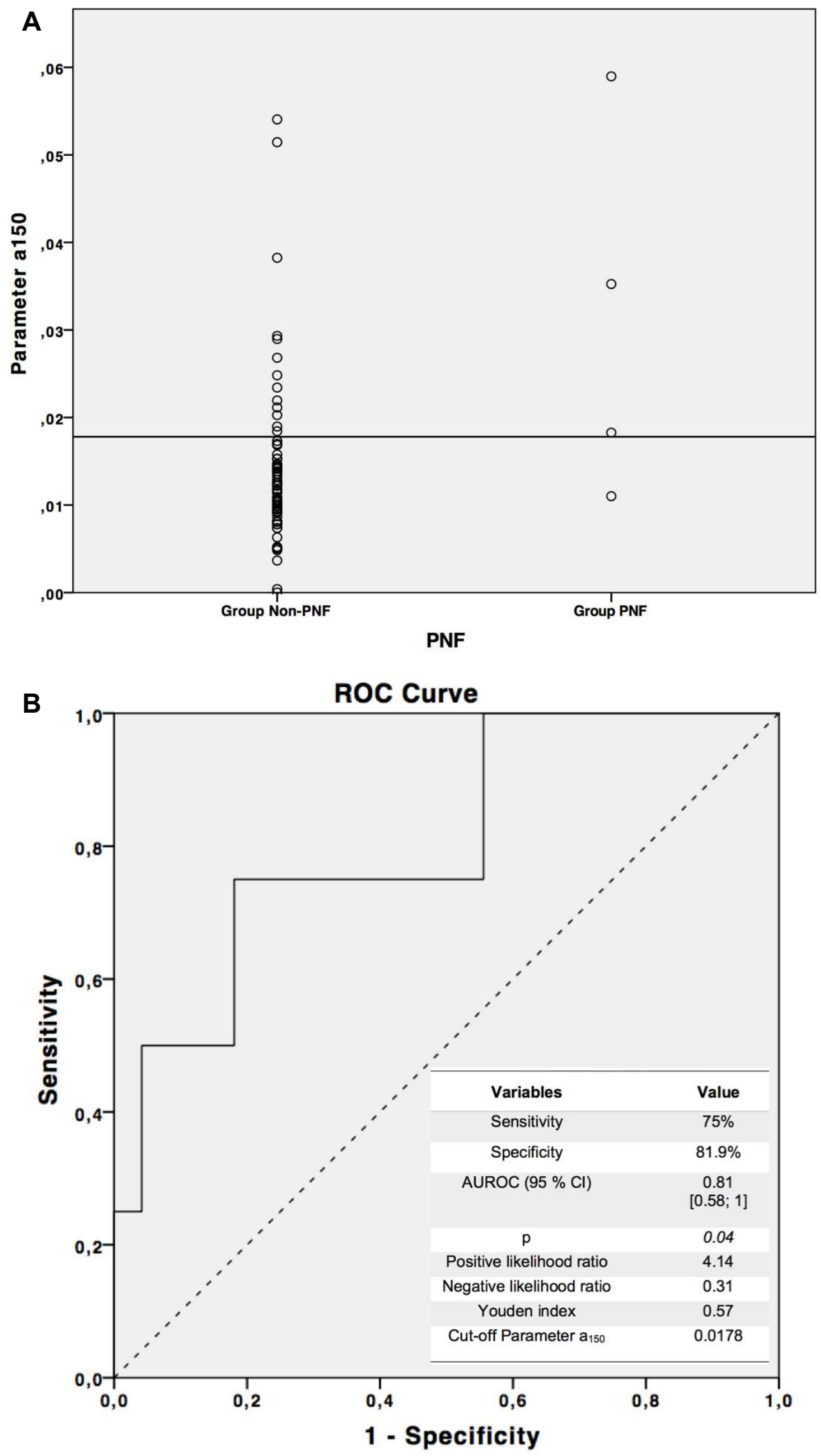